\title{
DIE BRÜDER DES DEUTSCHEN ORDENS IN ITALIEN
}

\section{KEYWORDS}

Teutonic Order; Medieval Prosopography; Medieval Italy; Medieval Germany; Career; History of the Administration; Genealogy

国 ie Geschichte des Deutschen Ordens in Italien, die während der letzten zwanzig Jahre in ein neues Licht gerückt wurde ${ }^{1}$, ist keineswegs eine lokalhistorische Thematik. Auf der Halbinsel und in Sizilien haben wir es mit einem Gebiet zu tun, das geographisch zwischen dem Heiligen Land und Preußen liegt, während es historisch bei der Verlagerung des Schwerpunkts des mittelalterlichen Deutschen Ordens vom Mittelmeer zur Ostsee eine wichtige Rolle spielte. ${ }^{2}$ Die zahlreichen in Italien vorhandenen Archivquellen ${ }^{3}$ enthalten vielfältige Informationen zu einer Reihe von Themen, zu denen auch die Geschichte des lokalen Ordenspersonals gehört. Diese Urkunden ermöglichen prosopographische Stu-

1 Für den status quaestionis siehe H. Houben, Recenti sviluppi storiografici su un tema controverso: l'Ordine Teutonico, Nuova Rivista Storica 89 (2005), 1, S. 125-142; K. Toomaspoeg, Die Behauptung des Deutschen Ordens in Italien, in: Herrschaft, Netzwerke, Brüder des Deutschen Ordens im Mittelalter und Neuzeit. Vorträge der Tagung der Internationalen Historischen Kommission zur Erforschung des Deutschen Ordens in Marburg 2010 (Quellen und Studien zur Geschichte des Deutschen Ordens 72, Veröffentlichungen der Internationalen Historischen Kommission zur Erforschung des Deutschen Ordens 12), hrsg. v. K. Militzer, Weimar 2012, S. 133-148.

2 Zu dieser Thematik siehe K. Forstreuter, Der Deutsche Orden am Mittelmeer (Quellen und Studien zur Geschichte des Deutschen Ordens 2), Bonn 1967; Der Deutsche Orden zwischen Mittelmeerraum und Baltikum. Begegnungen und Konfrontationen zwischen Religionen, Völkern und Kulturen (Acta Theutonica 5), hrsg. v. H. Houben, K. Toomaspoeg, Galatina 2008.

3 Siehe K. Toomaspoeg, Die Urkunden des Deutschen Ordens in Italien, in: Das virtuelle Archiv des Deutschen Ordens. Beiträge einer Internationalen Tagung im Staatsarchiv Ludwigsburg am 11. und 12. April 2013, hrsg. v. M. M. Rückert, Stuttgart 2014, S. 113-128. 
dien, die uns in ein perspektivenreiches Forschungsgebiet führen ${ }^{4}$ und auch die allgemeine Geschichte der mittelalterlichen geistlichen Ritterorden bereichern. ${ }^{5}$ Allerdings muss man berücksichtigen, dass eine mittelalterliche Prosopographie keineswegs mit einer zeitgenössischen statistischen Forschung vergleichbar ist. Ihre Basisdaten sind oft diskontinuierlich und unklar, und eine 'mathematische' Sicherheit wird sie niemals erreichen. Jedoch hindert uns dies nicht daran, einerseits die Gesamttendenzen zu beobachten und andererseits auf der Basis der besser dokumentierten Epochen und Personen glaubwürdige Schlussfolgerungen vorzuschlagen.

4 N. Jaspert, Military Orders and social history: Some introductory thoughts, in: As Ordens Militares. Freires, Guerreiros,Cavaleiros. Actas do VI Encontro sobre Ordens Militares. Palmela, 10 a 14 de março de 2010, hrsg. v. I. C. Ferreira Fernandes, Palmela 2012, vol. II, S. 495-517, hier S. 517.

5 Zur Prosopographie der mittelalterlichen geistlichen Ritterorden siehe u. a. D. Wojtecki, Studien zur Personengeschichte des Deutschen Ordens im 13. Jabrhundert (Quellen und Studien zur Geschichte des östlichen Europa 3), Wiesbaden 1971; M. L. Bulst-Thiele, Sacrae domus militiae templi hierosolymitani magistri: Untersuchungen zur Geschichte des Templerordens 1118/19-1314 (Abhandlungen der Akademie der Wissenschaften in Göttingen, 3. Folge, Philologisch-historische Klasse 86), Göttingen 1974; F. Benninghoven, Zur Zabl und Standortverteilung der Brüder des Deutschen Ordens in den Balleien um 1400, in: Preußenland 26 (1988), S. 1-20; Ritterbrüder im livländischen Zweig des Deutschen Ordens, hrsg. v. L. Fenske, K. Militzer, Köln-Weimar-Wien 1993; S. Neitmann, Von der Grafschaft Mark nach Livland. Ritterbrüder aus Westfalen im Livländischen Deutschen Orden, Köln-Weimar-Wien 1993; K. Borchardt, The Hospitallers, Bohemia, and the Empire, 1250-1330, in: Mendicants, Military Orders and Regionalism in Medieval Europe, hrsg. v. J. Sarnowsky, Aldershot 1999, S. 201-231; B. Jähnig, Deutscher Adel und Deutscher Orden. Probleme der Familienidentifizierung und Verwandtenversorgung, in: Aequilibrium mediaevale. Symposion anlässlich des 65. Geburtstages von Carl August Lückerath, hrsg. v. G. Christ, Idstein 2003, S. 61-79. Häufig wird diese Thematik am Rande von Monographien zur Territorialgeschichte behandelt, so z. B.: B. Klebes, Der Deutsche Orden in der Region Mergentheim im Mittelalter. Kommende, Stadt-und Territorialherrschaft (1219/20 - ca. 1525) (Quellen und Studien zur Geschichte des Deutschen Ordens 58), Marburg 2002; oder P. Bonneaud, Le prieuré de Catalogne, le couvent de Rhodes et la couronne d'Aragon, 1415-1447, Millau 2004. Für Italien siehe K. Toomaspoeg, Les premiers commandeurs de l'Ordre Teutonique en Sicile (1202-1291). Évolution de la titulature, origines géographiques et sociales, Mélanges de l'Ecole française de Rome. Moyen Âge 109 (1997), 2, S. 443-461; J.-E. Beuttel, Der Generalprokurator des Deutschen Ordens an der römische Kurie. Amt, Funktionen, personelles Umfeld und Finanzierung (Quellen und Studien zur Geschichte des Deutschen Ordens 55), Marburg 1999; H. Houben, Die Landkomture der Deutschordensballei Apulien (1225-1474), in: Sacra Militia. Rivista di storia degli ordini militari 2 (2001), S. 116-154; K. Toomaspoeg, La fondazione della provincia di "Lombardia" dell'Ordine dei Cavalieri Teutonici (secoli XIII-XIV), in: Sacra Militia. Rivista di storia degli ordini militari 3 (2003), S. 111-159, hier S. 146-148. 
Der vorliegende Beitrag stellt die ersten Ergebnisse einer Forschung vor, die mehr als zehn Jahre gedauert hat und jetzt endlich druckfertig vorliegt. ${ }^{6}$ Was hier beobachtet werden kann, sind die vorhandenen statistischen und biographischen Auskünfte zum Ordenspersonal in Italien, mit einem besonderen Interesse für die Epoche, in der die italienischen Ordensballeien Teil des Deutschmeistertums waren, d. h. von ca. 1365 bis zum ersten Viertel des 16. Jahrhunderts. Dieser Zeitraum ist viel besser dokumentiert als der vorhergehende, wobei es wichtig ist, dass die italienischen Urkunden durch zahlreiche Quellen aus Archiven deutschsprachiger Gebiete ergänzt werden können. So kann man die historischen Entwicklungen des Ordenspersonal genauer beobachten, indem man viele Indizien zur Zugehörigkeit der auf der Halbinsel tätigen Ordensbrüder zu einem Netzwerk von Menschen dies- und jenseits den Alpen findet, was hier überprüft werden soll.

\section{BASISDATEN}

Unsere Studie basiert auf einer Liste von 580 bekannten Mitgliedern des Deutschen Ordens in Italien, die Ergebnis einer Auswahl ist. Die Ordensbrüder der Ballei An der Etsch und im Gebirge (Südtirol) werden hier nicht berücksichtigt, da diese Ballei zu einem ganz anderen - überwiegend deutschsprachigen - Raum gehörte und sich durch ihre politische, religiöse und soziale Geschichte von anderen Ordensbesitzungen auf der Halbinsel stark unterschied. Dagegen werden die Brüder der Kommende Brixenei (heute Precenicco, Provinz Udine) im Friaul, die zwar einen Sonderfall darstellen, jedoch von der 'italienischen' Ballei Lamparten (Lombardei) abhängig waren, und die Generalprokuratoren des Deutschen Ordens an der päpstlichen Kurie aus der Zeit des avignonesischen Papsttums berücksichtigt. Insgesamt haben wir es demnach mit fünf verschiedenen Verwaltungseinheiten zu tun: den Ordensballeien Sizilien, Apulien, Rom und Lamparten sowie dem Sitz des Generalprokurators des Ordens an der päpstlichen Kurie.

Die chronologischen Grenzen der Untersuchung gehen vom Jahr 1202, als in Palermo zum ersten Mal ein Bruder des Deutschen Ordens dokumentiert ist ${ }^{7}$, bis 1534, dem Todesdatum des Balleistatthalters in Lamparten Nikasius von Ro-

6 K. Toomaspoeg, Der Deutsche Orden und seine Brüder in Italien (Quellen und Studien zur Geschichte des Deutschen Ordens) [im Druck].

71202 April 17. G. Mandalà, M. Moscone, Tra latini, greci e 'arabici': ricerche su scrittura e cultura a Palermo fra XII e XIII secolo, in: Segno e testo. International Journal of Manuscripts and Text Transmission 7 (2009), S. 143-238, Nr. I, S. 232-234. 
senau ${ }^{8}$ und des Komturs in Brixenei, Heinrich Schilling. ${ }^{9}$ Die später im Friaul, in Rom und anderswo in den Quellen vorkommenden Ordensmitglieder, die in der Geschichte des Deutschen Ordens teilweise eine wichtige Rolle gespielt haben, wie der Komtur in Brixenei Johann Kobenzl von Prosegg (zweite Hälfte des 16. Jahrhunderts) werden hier nicht berücksichtigt.

Die Ordensmitglieder kann man in verschiedene Kategorien einteilen (Abb. 1). Die Mehrzahl von ihnen waren „einfache“ Priester und Ritter der einzelnen Balleien. Dazu ist zu bemerken, dass der genaue Status eines Bruders nur in $30 \%$ aller Fälle eindeutig zu bestimmen ist. Graumäntler kommen nur sehr selten, insgesamt vier Mal vor. ${ }^{10}$ Vor allem geht es um die Komture der einzelnen Ordenskommenden und Landkomture der Balleien. Sie sind relativ gut dokumentiert, da die Ordensurkunden meistens von ihnen ausgestellt oder gar unterschrieben wurden.

Als Amtsträger einer Ballei findet man in Italien, außer den Komturen, noch drei andere Kategorien: Balleistatthalter, Prokuratoren und, seit dem 15. Jahrhundert, Tressler. Baumeister, Fischmeister oder ähnliche Amtsträger gab es in Italien dagegen nicht. Kleinere, aber interessante Gruppen bildeten die Generalprokuratoren und andere Vertreter des Ordens an der Kurie ${ }^{11}$ sowie die hoch- und deutschmeisterlichen Visitatoren. ${ }^{12}$ Schließlich gab es an den großen italienischen Universitäten auch Ordensmitglieder als Studenten. Im Grunde teilt sich das gan-

8 Wien, Zentralarchiv des Deutschen Ordens, Ordensstandsverzeichnis, Liste der 1508/1534 verstorbenen Deutschordensritter.

9 Schilling wurde am 8. April 1534 in Brixenei getötet: ebda.

10 Diese Männer sind Orreditus (Ballei Lamparten, 1280 September 8., Padua, Archivio di Stato, Corporazioni religiose soppresse, Gesuiti, Bd. 136, Nr. 9; Bd. 138, Nr. 12), Kaspar Hut aus Preußen (Lamparten und Sizilien, 1448 Oktober 21., ebd., Bd. 167, Nr. 18; 1448 November 21., ebd., Bd. 160, Nr. 3; 1451 August, Visitationen im Deutschen Orden im Mittelalter, Bd. II: 1450-1519 (Quellen und Studien zur Geschichte des Deutschen Ordens 50/II, Veröffentlichungen der Internationalen historischen Kommission zur Erforschung des Deutschen Ordens 10/II), hrsg. v. M. Biskup, I. Janosz-Biskupova, Marburg 2004, Nr. 163, S. $96-97$ (hier S. 97)), Lamprecht (Apulien, 1451 August, ebd., Nr. 163, S. 96-97 (hier S. 96)) und Berthold Hetthikaw (Lamparten, 1451 (nach November 20.), ebd., Nr. 175, S. 119-138 (hier S. 128)). Drei von diesen vier Ordensbrüdern sind nur durch den Bericht der hochmeisterlichen Visitation von 1451 bekannt, und die deutschmeisterlichen Quellen erwähnen niemals den Status eines Graumäntlers. Im Fall des Kaspar Hut aus Preußen wird der Bruder von den hochmeisterlichen Visitatoren als Graumäntler bezeichnet, in den anderen Quellen kommt er aber nur als „Bruder" vor.

11 Siehe Beuttel (wie Anm. 5).

12 Siehe Visitationen im Deutschen Orden im Mittelalter, hrsg. v. Marian Biskup, I. Janosz-Biskupova, Bd. I: 1236-1449 (Quellen und Studien zur Geschichte des Deutschen Ordens 50/I, Veröffentlichungen der Internationalen historischen Kommission zur Erforschung des Deutschen Ordens 10/I), Marburg 2002, S. xiii-1. 
ze Material in zwei Gruppen, die getrennt untersucht werden sollen: einerseits die Brüder und Komture der einzelnen Balleien und die Visitatoren des Ordens, andererseits die Generalprokuratoren in Rom und die in Italien studierenden Ordensmitglieder. ${ }^{13}$

Die Gesamtzahl von 580 Ordensbrüdern in Italien muss man jedoch relativieren. Vor allem sind viele Brüder (ca. 30\%) nur mit ihrem Vornamen bekannt (z. B. gibt es 16 „Johann“ und 15 „Konrad“), so dass man in vielen Fällen zu keiner befriedigenden Identifikation kommt und davon ausgehen kann, dass derselbe Bruder mehrmals in der Liste vorkommt. So reduziert sich die Zahl der Brüder. Gleichzeitig ist aber auch sicher, dass nicht alle Brüder in den Quellen erwähnt sind. Die Urkunden, hauptsächlich Notariatsinstrumente, wurden relativ selten von mehreren Brüdern bezeugt, und normalerweise war ein Provinzoberer oder lokaler Komtur völlig ausreichend. Hinzu kommt die Tatsache, dass die Archive einiger Kommenden im Laufe der Zeit verloren gegangen sind und dass in den Haupthäusern die Kontinuität der Archivquellen nicht gesichert ist und somit manche Epochen viel schlechter dokumentiert sind als andere. So wurde z. B. in der Ballei Sizilien zwischen 1250 und 1350 eine beträchtliche Zahl von Urkunden ausgestellt (bis zu 28 pro Jahr), gegenüber einem erhaltenen Durchschnitt von nur $1-2$ pro Jahr zwischen 1400 und $1500 .^{14}$

Aufgrund dieser Überlegungen darf man vermuten, dass der Deutsche Orden auf der Halbinsel ständig etwa 30 bis 40 Brüder zählte. Im Jahr 1451, als das Personal aller drei italienischen Balleien von Visitatoren namentlich erfasst wurde, war die Lage folgende: In Sizilien gab es $7^{15}$, in Apulien $9^{16}$ und in Lamparten 10 Brüder. ${ }^{17}$ Wenn man die übrigen vorhandenen Quellen hinzuzieht, kommt man zu einer Zahl von mindestens 4 und maximal 12 Ordensmitgliedern pro Ballei und kann annehmen, dass in jeder Ballei normalerweise circa 10 Brüder residierten, insgesamt also rund 30. Dazu kommen die Vertreter des Deutschen Ordens in Rom und im 15. Jahrhundert auch die zum Orden gehörenden Studenten, deren genaue Zahl wohl unbekannt bleiben wird.

13 Siehe K. Militzer, Die Beziehungen des Deutschen Ordens zu den Universitäten, besonders zur Kölner Universität, in: Die Spiritualität der Ritterorden im Mittelalter, hrsg. v. Z. H. Nowak (Ordines militares. Colloquia Torunensia Historica VII), Toruń 1993, S. 253-269.

14 Siehe K. Toomaspoeg, Les Teutoniques en Sicile (1197-1492) (Collection de l'École française de Rome 321), Rom 2003.

15 Visitationen, Bd. II (wie Anm. 10), Nr. 163, S. 96-97.

16 Ebd.

17 Ebd., Nr. 175, S. 128. 


\section{Herkunft des Ordenspersonals}

Im Rahmen des Forschungsvorhabens wurde ein Repertorium des Ordenspersonals geschaffen (Abb. 2): Für jeden Bruder werden seine biographischen Daten, seine Karriere innerhalb des Ordens und die vorhandenen italienischen und anderen Quellen aufgezeigt. Ein grundlegendes Problem war die Identifizierung der Herkunft der einzelnen Ordensmitglieder, die oft sehr schwierig ist.

Dies liegt vor allem daran, dass die meistens von lokalen Notaren geschriebenen italienischen Quellen Wirtschaftsvorgänge betreffen, die nur in einigen glücklichen Fällen direkt von Ordensbrüdern unterschrieben wurden. Die italienischen Notare schrieben die deutschen Namen meist "phonetisch“ auf, so dass man Cuprichci wie „Kirchberg“ und Perlengingem wie „Berlichingen“ lesen muss. Außerdem sind heute nicht alle Urkunden im Original überliefert: Viele sind nur als Kopien in Notariatsregistern erhalten, in denen der Notar den Inhalt seiner Akten schnell und nicht immer sorgfältig aufgeschrieben hat; viele andere finden sich in neuzeitlichen Kopialbüchern, die oft große Probleme bereiten. In Apulien sind die Originale des ehemaligen Ordensarchivs verloren gegangen; daher ist es notwendig, die von neuzeitlichen Historikern veröffentlichten oder einfach kopierten Versionen zu benutzen. ${ }^{18}$ In letzterem Fall kommt man oft an das Ende einer Kette von Irrtümern, die mit der Originalurkunde anfangen und mit den Editionen und Repertorien des 19. und 20. Jahrhunderts enden.

Sind die vorhandenen Nachnamen entschlüsselt, so kommt man zum Problem ihrer Interpretation. Es gibt etliche Namen, die „italienisch“ aussehen, tatsächlich aber aus dem deutschsprachigen Raum stammen, wie Romarado, wohl Romrod, eine Marburger Familie ${ }^{19}$, oder Castelleone, wohl Kastellaun im Hunsrück. ${ }^{20}$ Wenn die Namen einer genaueren Örtlichkeit entsprechen, kommt man zu einer der Hauptfragen der mittelalterlichen prosopographischen Untersuchungen: Handelt es sich um einen Mann mit dem Namen seines Herkunftsorts oder um einen Familiennamen? So kam Burchardt von Masmünster nicht aus der heutigen

18 Siehe H. Houben, Zur Geschichte der Deutschordensballei Apulien. Abschriften und Regesten verlorener Urkunden aus Neapel in Graz und Wien, Mitteilungen des Instituts für Österreichische Geschichtsforschung 107 (1999), 1-2, S. 50-110; Linventario dell'archivio di S. Leonardo di Siponto (ms. Brindisi, Bibl. De Leo B 61): una fonte per la storia dell'Ordine Teutonico in Puglia (Acta Theutonica 6), hrsg. v. H. Houben, V. Pascazio, Galatina 2010.

19 Houben, Die Landkomture (wie Anm. 5), S. 127, 139.

20 Toomaspoeg, Les Teutoniques (wie Anm. 14), Nr. 34, S. 461. 
Masevaux, sondern war Mitglied einer bekannten an anderem Ort residierenden Adelsfamilie. $^{21}$

Eine weitere nicht unwichtige Tatsache ist, dass mehrere Ordensbrüder in den Quellen mit dem Namen ihres vorigen Wirkungsortes vorkommen. Das gilt für alle Brüder mit Namen wie de Brundusio („aus Brindisi“), de Melfia („aus Mel-

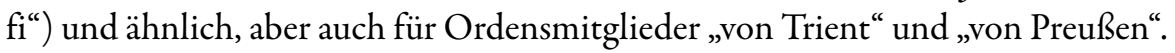
Schließlich tauchen einige Ortsnamen viel zu häufig auf, um auf dieser Basis Schlussfolgerungen ziehen zu können. So wies Stefan Selzer in seiner Studie über deutsche Söldner im mittelalterlichen Italien darauf hin, dass z. B. ein Johann von Falkenberg „sich beispielsweise mit mindestens zehn Burgen im deutschen Sprachraum in Verbindung bringen lässt“ “.22

Eine allein auf den italienischen Quellen basierende Untersuchung würde nur ganz unsichere Daten liefern. Es ist daher nötig, die vorhandenen Informationen mit dem Archivmaterial nördlich der Alpen zu vervollständigen. Die heutigen und ehemaligen Archive des Deutschen Ordens in Wien und Ludwigsburg bieten in dieser Hinsicht eine wichtige Hilfe; dazu kommen natürlich alle vorhandenen Urkundeneditionen und Regestenwerke, die Studien zur Geschichte des Ordens und seiner einzelnen Balleien und Häuser sowie das vorhandene prosopographische Vergleichsmaterial.

Aufgabe unserer Studie war die Identifizierung der einzelnen Ordensmitglieder auf der italienischen Halbinsel und in Sizilien. Es geht um vier Ebenen von Identifizierung: 1) Zunächst findet man einen festen Kern von 46 Personen, für die eine Reihe von biographischen Auskünften, wie Geburts- und Todesdatum, Datum des Ordenseintritts usw. vorhanden sind, so dass sie als „,bekannte Persönlichkeiten" gelten. 2) Sie sind auch Teil der zweiten Ebene mit 147 Personen, deren Genealogie bekannt ist. 3) die dritte Ebene besteht aus 193 Männer mit bekanntem Herkunftsort. 4) Schließlich haben alle 313 ,identifizierte“ Personen als gemeinsame Charakteristik, dass ihre geographische und regionale Herkunft bekannt ist.

21 Burchardt, Ordensbruder in Sizilien 1289-1290, war eines der ersten bekannten Mitglieder der ursprünglich aus der gleichnamigen Stadt im Elsass stammenden Adelsfamilie Masmünster: Rudolf von Masmünster war 1328-1330 Prior des Johanniterordens in Deutschland (Borchardt, The Hospitallers (wie Anm. 5), S. 227). Johann von Masmünster war 1379-1387 Ordensbruder in Preußen, 1379-1380 und 1386-1387 Vogt in Fischau und 1380-1383 Fischmeister des Hauses Elbing (Nürnberg, Germanisches Nationalmuseum, Sammlung Hartmann).

22 S. Selzer, Deutsche Söldner im Italien des Trecento (Bibliothek des Deutschen Historischen Instituts in Rom 98), Tübingen 2001, S. 213. 
Um die regionale Herkunft der Brüder darstellen zu können, wurde eine Reihe von geographischen Einheiten ausgewählt (Abb. 3). Diese Auswahl basiert auf der von Peter Moraw geschaffenen und Stephan Selzer weiterentwickelten Einteilung des Reiches in vierzehn Großregionen ${ }^{23}$ und auf den eigenen Verwaltungsstrukturen des Deutschen Ordens.

Die Ergebnisse unserer Studie werden mithilfe von Graphiken verdeutlicht, welche die einzelnen Epochen der Geschichte des Deutschen Ordens auf der italienischen Halbinsel darstellen (Abb. 4).

Die erste ist die Periode, in der Italien sich ganz im Zentrum des Deutschen Ordens befand: Von 1291 bis 1309 residierte der Hochmeister sogar selbst auf der Halbinsel, in Venedig. Diese Epoche ist durch eine Vielzahl von Herkunftsgebieten charakterisiert, von denen einige nur in dieser Zeit eine wichtige Rolle spielten, später aber relativ marginal blieben. Am bedeutendsten war das nordrheinische Gebiet (insgesamt 10\%), ferner eine nicht unbeträchtliche Anzahl von Italienern (5\%). All diese Daten werden aber von einer Mehrzahl von nicht identifizierten Namen überschattet.

In der zweiten Phase, ab 1310, als der Hochmeister nördlich der Alpen residierte, erreichen zwar Personen aus dem Mittelrheingebiet eine herausragende Stellung (10\%), quantitativ besonders stark ist jedoch die Präsenz aus niederheinischen Gebieten (17\%). Auch steigt die Zahl der Brüder aus den Balleien Franken und Hessen (11\%), und gleichzeitig verschwinden die Italiener fast völlig aus den Quellen.

Während der deutschmeisterlichen Verwaltung (ab ca. 1365) kommt fast die Hälfte des Personals aus Franken, Schwaben und Hessen; gleichzeitig sind die einzigen anderen wichtigen Herkunftsgebiete der Mittelrhein und Tirol (letzteres aber nur in der Ballei Lamparten). Dieselbe Tendenz ist auch in der letzten Phase sichtbar, als sich die Rolle der Brüder aus deutschmeisterlichen Gebieten auf 55\% erhöht. Dabei ist natürlich zu bedenken, dass der Prokuratorensitz in Rom eine eigene Personalgeschichte hatte, denn meistens - wenngleich nicht immer - kam sein Personal aus Preußen und Livland. Das erklärt die ständige Anwesenheit, seit 1309 , von $10 \%$ von Brüdern aus diesen Gebieten.

Auch wenn die Daten des 13. Jahrhunderts sehr unsicher bleiben, ist es möglich, hier einen Prozess zu beobachten, in dem die Rheinländer und Holländer während des 14. Jahrhunderts langsam durch Brüder aus den deutschmeisterlichen

23 P. Moraw, Die Entfaltung der deutschen Territorien im 14. und 15. Jahrhundert, in: Landesherrliche Kanzleien im Spätmittelalter. Referate zum VI. Internationalen Kongreß für Diplomatik München 1983 (Münchener Beiträge zur Mediävistik und Renaissance-Forschung 35), Bd. I, München 1984, S. 61-108, hier, S. 96; Selzer (wie Anm. 22), S. 214. 
Balleien Hessen und Franken ersetzt werden (Abb. 5). Dieselbe Beobachtung gilt auch für die Herkunftsstädte der Ordensbrüder in Italien, wo man die wechselnde Rolle der Städte Köln und Nürnberg feststellen kann (Abb. 6).

Die vorgelegten Daten erlauben uns auch, zwei Hypothesen aufzustellen. Zuallererst könnte die Übergabe der Verwaltung der italienischen Balleien an den Deutschmeister um 1365 auch dadurch verursacht worden sein, dass es bereits damals in Italien eine beträchtliche Anzahl von Brüdern aus deutschmeisterlichen Gebieten gab. Zum zweiten zeigen zwei Konflikte aus der ersten Hälfte des 14. Jahrhunderts in den Balleien Apulien und Sizilien, dass die Beziehungen zwischen Rheinländern und Süddeutschen in Italien nicht immer gut waren: Im März 1327 haben die hochmeisterlichen Visitatoren den Landkomtur von Sizilien Wilhelm von Cuyk, einen Niederländer aus der Adelsfamilie Cuyk an der Maas, seines Amtes enthoben, und der Visitator Otto von Bissingen aus Schwaben hat die Ballei für ein Jahr selbst verwaltet. ${ }^{24} 1334$ haben einige Brüder den Sitz des Landkomturs in Apulien in der Stadt Barletta besetzt, seine Güter usurpiert und die dem Landkomtur treu gebliebenen Brüder eingesperrt ${ }^{25}$; der Hauptschuldige war ein Rheinländer, Nikolaus von Cuesin, der Landkomtur aber ein Süddeutscher, Walram von Hornberg.

\section{Die italienischen Balleien im Deutschmeistertum}

Kommen wir jetzt zur Frage der Netzwerke zur Zeit der deutschmeisterlichen Verwaltung nach ca. 1365. Zuerst sollte man daran erinnern, dass Italien seither immer nur eine Zwischenetappe in der Karriere eines Ordensbruders war, das heißt, nur sehr wenige Brüder wurden auf der Halbinsel rekrutiert, und nur einige sind hier gestorben.

Zwei Graphiken stellen die Amtsdauer der Ordensmitglieder in Italien dar (Abb. 7). Die erste zeigt den allgemeinen Trend, die zweite die Amtsdauer der Landkomture. Eine Mehrzahl von Personen, wie „einfache“ Brüder, Komture, Landkomture, Vertreter des Ordens in Rom und andere, wird nur einmal in den Quellen erwähnt, eine Zahl, die im Fall der besser dokumentierten Landkomture sehr niedrig ist, im Fall der Brüder, die nicht das Amt eines Komturs ausgeübt haben, wie die Basiskategorie zeigt, aber bis auf 66\% steigt. Der Hauptteil der

\footnotetext{
241327 März 17. Palermo, Archivio di Stato, Tabulario della Magione, 603; ebd., Notai Defunti, Ruggero Citella, Bd. 76, Fol. 87r, Nr. 8; Visitationen, Bd. I (wie Anm. 12), S. 10; 1328 April 20., Palermo, Archivio di Stato, Tabulario della Magione, 604, 606.

251335 September 13.; Houben, Zur Geschichte (wie Anm. 18), Nr. 35, S. 104-106.
} 
Landkomture und der in den Quellen mehrmals vorkommenden Brüder ist für einen Zeitraum von 1 bis 9 Jahren in Italien geblieben. Von den Landkomturen weilten sehr wenige (vier) für nur ein Jahr auf der Halbinsel; die Mehrzahl kommt in den Quellen für zwei oder drei Jahre vor. Eine mehr als 10 Jahre dauernde Amtszeit ist vergleichsweise häufig: Unter den Brüdern sind viele bis zu 11 Jahren in Italien geblieben, eine Amtszeit von mehr als 18 Jahren ist dagegen selten. Im Fall der Landkomture liegt der Höhepunkt zwischen 11 und 14 Jahren (insgesamt 37 Namen).

Um festzustellen, warum die Brüder nur einige Jahre in Italien geblieben sind, muss man ihre vorigen und späteren Funktionen untersuchen, was in einigen Fällen möglich ist (Abb. 8). Nehmen wir ein ganz typisches Beispiel einer Karriere innerhalb des Deutschen Ordens im 14. und 15. Jahrhundert: Ludwig Schenk von Schenkenstein, mit Herkunft und Karrierebeginn in Franken (Ludwig, Sohn Georg Schenks von Schenkenstein des Älteren und Barbaras von Zipplingen, noch minderjährig um 1430 in Franken in den Orden eingetreten ${ }^{26}$ ), dann eine kurze Zeit in Preußen, wo er 1451 und 1453 als Ritterbruder vorkommt ${ }^{27}$, und schließlich eine Komturstelle in Italien, zuerst in Lamparten und dann in Apulien. ${ }^{28}$

Als Vergleich kann ein ganz typisches Beispiel der Karriere eines Generalprokurators in Rom dienen: Johann Tiergart (Prokurator 1419-1428), aus dem Stadtpatriziat von Danzig, auch hier mit einer anderen Reihe von charakteristischen Elementen wie Studium in Italien (Bologna), Papstdienst (als Legat in Spoleto) und Zugehörigkeit zur Kirchenhierarchie (als Bischof von Kurland) ${ }^{29}$

Im 14. Jahrhundert war es noch üblich, dass ein Ordensbruder seine Karriere in Italien anfing: Heinrich Reck von Hegi, aus einem bekannten Adelsgeschlecht in Winterthur und Freiburg im Breisgau ${ }^{30}$, kommt zuerst in Lamparten vor, wo er 1355-1357 als Landkomtur urkundet; 1359-1362 war er Komtur in Ulm

26 Nürnberg, Germanisches Nationalmuseum, Sammlung Hartmann. Siehe auch Ludwigsburg, Staatsarchiv, B 422, U 11, 12, 13; B 503 I U 841; B 389 Bü 1052.

27 Visitationen, Bd. II (wie Anm. 10), S. 122.

28 Siehe M. Fanti, G. Roversi, S. Maria degli Alemanni in Bologna, Bologna 1969, S. 19-21; H. Houben, Federico II, l'Ordine Teutonico e il "castrum" di Mesagne: nuove notizie da vecchi documenti, Castrum Medianum 6 (1998), S. 27-69; ders., Die Landkomture (wie Anm. 5), S. 151; Visitationen, Bd. II (wie Anm. 10), S. 122.

29 H. Freytag, Die Geschäftsträger des Deutschen Ordens an der Römischen Kurie von 1309 bis 1525, Zeitschrift des Westpreußischen Geschichtsvereins 49 (1907), S. 185-220, hier S. $202-$ -203; Berichte der Generalprokuratoren des Deutschen Ordens an der Kurie (Veröffentlichungen der Niedersächsischen Archivverwaltung 21), Bd. III, Halbbd. 1, hrsg. v. K. Forstreuter, H. Koeppen, Göttingen 1966, S. 23-45; Beuttel (wie Anm. 5), S. 55 f.

30 Nürnberg, Germanisches Nationalmuseum, Sammlung Hartmann. 
und zuletzt, ab 1364, Landkomtur in Elsass-Burgund. ${ }^{31} \mathrm{Im}$ 15. und vor allem im 16. Jahrhundert begannen die Ordensmitglieder ihre Karriere hingegen in der Regel im Deutschmeistertum: So war Ortolf von Zogenreuth, Mitglied der Adelsfamilie von Zogenreuth aus Eschenbach in der Oberpfalz (Landkreis Neustadt an der Waldnaab), zunächst 1420-1425 Hauskomtur in Nürnberg und anschließend Landkomtur; zuerst in Lamparten, danach in Sizilien. Vinzenz Leubint aus Neustadt (an der Weinstraße) in der Pfalz kommt in den Quellen zuerst als Ritterbruder der Ballei Hessen vor, wo er 1446-1459 als Kellner und Küchenmeister der Kommende Marburg an der Lahn und Trapier in Griefstedt amtierte; seit spätestens 1464 war er Balleistatthalter in Lamparten, 1467-1478 dort Landkomtur und 1473-1474 gleichzeitig Balleistatthalter in Apulien und Landkomtur „in ganze Italien und in Morea" (Griechenland). ${ }^{32}$

Wichtig ist, dass die Brüder auch innerhalb von Italien eine „Karriere“ durchliefen. In einer Ballei wechselte man von einer Kommende zur anderen, und mehrere „einfache“ Brüder wurden Komture und umgekehrt. Zwischen den drei Balleien der Halbinsel gab es eine regelmäßige Bewegung von Norden nach Süden. Dabei ging es nicht um Strafversetzungen von Brüdern nach Süditalien, wie man vermuten könnte, sondern um die Tatsache, dass die norditalienische Ballei Lamparten die ganze Halbinsel mit Personal versorgte. In den meisten Fällen kam ein Bruder aus Deutschland zuerst nach Lamparten, von wo er dann nach Apulien oder Sizilien entsandt wurde, wie z. B. im angeführten Fall Ludwig Schenks von Schenkenstein.

Auch die soziale Herkunft der Ordensbrüder veränderte sich im Laufe der Zeit deutlich, ist aber vor dem 15. Jahrhundert nicht ausreichend dokumentiert. In der Epoche der deutschmeisterlichen Verwaltung in Italien haben wir es in den geprüften Fällen mit drei sozialen Herkunftsgruppen zu tun: kleinere ritterliche Familien sowie adeliges und bürgerliches Stadtpatriziat.

Betrachten wir zuerst die ritterlichen Familien, so findet man in Italien einige interessante Beispiele wie das des Kraft von Seeburg, Priesterbruder in Apulien, der auch die Schwierigkeiten der Identifizierung des Ordenspersonals gut verdeutlicht. Kraft kommt als Priesterbruder und Komtur in San Leonrado di Siponto

31 Ulmisches Urkundenbuch, hrsg. v. F. Pressel, Bd. II, Tl. 2: Die Reichsstadt von 1315 bis 1378, Stuttgart 1900, Nr. 560; M. Tumler, Der Deutsche Orden in Werden Wachsen und Wirken bis 1400 mit einem Abriß der Geschichte des Ordens von 1400 bis zur neuesten Zeit, Wien 1955, S. 621 .

32 Siehe Forstreuter (wie Anm. 2), S. 131, 156; Fanti, Roversi (wie Anm. 28), S. 22-24; Beuttel (wie Anm. 5), S. 89; Houben, Die Landkomture (wie Anm. 5), S. 152. 
in der Ballei Apulien im Jahr 1394 vor. ${ }^{33}$ Ohne weitere Quellen wäre es unmöglich, seine Herkunft herauszufinden, wiewohl "Seeburg“ ein Name zahlreicher Orte ist. Ein gleichnamiger, vielleicht ein Verwandter, war 20-30 Jahre früher Söldner in Florenz und in Modena ${ }^{34}$; aber wir wissen nicht, woher er stammte. Zum Glück findet sich in Stuttgart eine Urkunde, mit der unser Kraft im September 1399 in Bad Urach (Landkreis Reutlingen) eine Transaktion seines Onkels Bercht von Seeburg bestätigte: Dieser hatte im August 1396, als Kraft in Italien weilte, alle von seinem Bruder (Vater Krafts) geerbten Güter und Rechte an Graf Eberhard III. von Württemberg verkauft. ${ }^{35}$ So handelte es sich also im Wesentlichen um eine Familie aus dem Dorf Seeburg, heute ein Stadtteil von Bad Urach.

Aus dem Ende des 14. Jahrhunderts stammt das Beispiel des Ulrich von Schmalenstein, welcher der erste deutschmeisterliche Landkomtur in Sizilien und Apulien war. Er stammte aus einer Familie von Edelknechten mit Besitz und Einkünften im Gebiet von Maulbronn und Tuttlingen, die seit der zweiten Hälfte des 13. Jahrhunderts in Dokumenten aus württembergischen Archiven vorkommt (Abb. 9). ${ }^{36}$

Die kleineren und mittleren Geschlechter von Rittern und Edelknechten aus dem heutigen Baden-Württemberg bildeten das Rückgrat des Personals der italienischen Balleien, jedoch war auch die Rolle des Stadtadels und sogar der bürgerlichen Stadtfamilien nicht zweitrangig. Im 15. und 16. Jahrhundert waren die zwei wichtigsten Herkunftssorte der Ordensbrüder in Italien die Städte Frankfurt am Main und besonders Nürnberg. Man kann beobachten (Abb. 10), dass es sich praktisch um ein Lexikon des nürnbergischen Patriziats im 15. Jahrhundert handelt, und im Stadtarchiv Nürnberg findet man interessante Auskünfte über diese Männer und ihre Familien, die alle auch eine Verbindung zur lokalen Ordenskommende besaßen.

Zur Zeit der deutschmeisterlichen Verwaltung in Italien stammten die Brüder der Ordensballeien in der Regel aus Familien mit langfristigen und dauerhaften

331394 November 2., Regesto di S. Leonardo di Siponto, hrsg. v. F. Camobreco (Regesta Chartarum Italiae 10), Rom 1913, Nr. 273, S. 201; s. Houben, Die Landkomture (wie Anm. 5), S. 145 .

34 Selzer (wie Anm. 22), S. 412, 419.

351399 September 30., Stuttgart, Hauptstaatsarchiv, A 602 (Württembergische Regesten), Nr. 13743.

36 Siehe die Urkunden von 1294 März 12., Stuttgart, Hauptstaatsarchiv, A 502, U 243, 1368 März 28.; ebd., A 602, Nr. 11215, 1390 November 5.; ebd., A 602, Nr. 11222, 1392 Februar 22.; ebd., A 602, Nr. 135731396 Januar 29.; ebd., A 502, U 741, 1326 Juli 26.; ebd., A 602, Nr. 11206, 1483 Oktober 21.; ebd., A 602, Nr 10468, und viele andere. Siehe auch Forstreuter (wie Anm. 2), S. 121, 133; Houben, Die Landkomture (wie Anm. 5), S. 144; Toomaspoeg, Les Teutoniques (wie Anm. 14), Nr. 172, S. 475. 
Beziehungen zu den Balleien Hessen und Franken, deren Mitglieder normalerweise auch in Preußen gedient haben. Nehmen wir die Beispiele des Geschlechts Heusenstamm, dem mindestens drei Ordensmitglieder entstammen (Abb. 11), oder der Familie Mengersreuth. ${ }^{37}$ In einigen Fällen ist die Liste der bekannten Ordensmitglieder mit derselben familiären Herkunft ziemlich lang. So im württembergischen Geschlecht Urbach, mit mindestens fünf bekannten Mitgliedern im Orden (Abb. 12). Man könnte zahlreiche andere Fälle hinzufügen, wie die der Familien Klingenfels ${ }^{38}$, Uissigheim ${ }^{39}$ oder Eyb ${ }^{40}$. Johann Gross von Trockau

37 Nikolaus Mengersreuth war 1430 Bruder in Apulien: 1430 Juni 13., Regesto di S. Leonardo (wie Anm. 33), Nr. 287, S. 216-217. Der Priester Nikolaus Mengersreuth (Mengosreuter) schwur im November 1376, dem Deutschen Orden Hilfe zu leisten (Die Urkunden des DeutschordensZentralarchivs in Wien. Regesten, hrsg. v. U. Arnold (Quellen und Studien zur Geschichte des Deutschen Ordens 60/I-III), Marburg 2006-2007, hier Bd. II, Nr. 2357, S. 723), Burkard von Mengersreuth war bis 1454 Ordensritter in Preußen und danach in der Ballei Franken (Nürnberg, Germanisches Nationalmuseum, Sammlung Hartmann).

38 Hengerard von Klingenfels, Mitglied des württembergischen Geschlechts aus Klingenfels an der Schmerach im Gebiet von Unteraspach (unweit Schwäbisch Hall), war Komtur und dann einfacher Bruder in Padua (Lamparten) 1379-1381. Lupold von Klingenfels war seit 1372 Bruder in der Ballei Franken (Die Urkunden des Deutschordens-Zentralarchivs (wie Anm. 37), Bd. II, Nr. 2280, S. 703), Kunz empfahl 1368 den Ordenseintritt des Kaspar von Dörzebach (ebd., Nr. 2226, S. 688) und 1372 den des Kunz Kuchemeister (ebd., Nr. 2286, S. 704), Michael war 1451 Komtur in Wiener Neustadt in Österreich (Visitationen, Bd. II (wie Anm. 10), S. 127).

39 Arnold von Uissigheim, aus einer Familie fränkischen Kleinadels (ursprünglich aus dem Dorf Uissigheim, heute Stadtviertel von Külsheim, Main-Tauber-Kreis), war 1390-1391 Landkomtur in Lamparten. Friedrich von Uissigheim war 1385 Ordensbruder in Mergentheim (Klebes (wie Anm. 5), S. 707) sowie Paul von Uissigheim 1426 (ebd., S. 708); dieser oder ein gleichnamiger (Pauel von Ussigkheym) war 1451 hospitalarius der Ordenskommende Nürnberg (Visitationen, Bd. II (wie Anm. 10), S. 127.

40 Gottschalk von Eyb, aus der Familie der Ritter von Eyb (häufig auch Iwe, Ywe, Ibe oder Wy, siehe H. Grimm, Eyb, fränkisches Adelsgeschlecht, in: Neue Deutsche Biographie, Bd. 4, Berlin 1959, S. 705), war 1396-1398 Landkomtur in Lamparten. Wilhelm von Eyb ist 1441 dank der Empfehlungen von Konrad und Ludwig von Eyb in den Orden eingetreten (Die Urkunden des Deutschordens-Zentralarchivs (wie Anm. 37), Bd. III, Nr. 3463, S. 1041) und war 1451 in Leyden anwesend (als Wilhelm von Wy, Visitationen, Bd. II (wie Anm. 10), S. 135), 1428 war Martin von Eyb war Überreiter in Eschenbach (Ludwigsburg, Staatsarchiv, JL 425, Bd. 27, Qu. 99), er oder ein Gleichnamiger war Komtur in Virnsberg ca. 1444-1464 (1444 Juni 25., ebd., JL 425, Bd. 3, Qu. 189, 1446 Februar 13.; ebd., JL 425, Bd. 3, Qu. 194, 1463 November 20.; ebd., JL 425, Bd. 27, Qu. 94, 1464 Juli 9.; ebd., JL 425, Bd. 27, Qu. 131; sein Epitaph findet sich in der Jakobskirche in Nürnberg: ebd., JL 425, Bd. 25, Qu. 16). Es geht um die Familie des Humanisten Albrecht von Eyb (geb. 1420), Autor des An viro sapienti uxor sit ducenda, der in Bologna, Padua und Pavia studiert hat, und des Juristen Anselm von Eyb (1444-1470), der 1468 eine Pilgerreise ins Heilige Lande unternahm (Europäische Reiseberichte des späten Mittelalters. Eine analytische Bibliographie (Kieler Werkstücke, Reihe D: Beiträge zur europäischen 
ist im Jahr 1452 zusammen mit seinen beiden Brüdern in den Deutschen Orden eingetreten. ${ }^{41}$

Einige der Herkunftsfamilien der Ordensbrüder in Italien sind dank ihrer Beziehungen zum Orden relativ berühmt geworden. Nehmen wir hier das Beispiel des Geschlechts Venningen aus dem Kraichgau ${ }^{42}$, das man nicht mit dem gleichnamigen Geschlecht aus dem Elsass verwechseln sollte ${ }^{43}$ und aus welchem zwei Deutschmeister stammen (Abb. 13). Oder die Familie Bobenhausen, die später auch einen Hochmeister des Deutschen Ordens hervorbachte. ${ }^{44}$ Schließlich noch zwei Beispiele von Priesterbrüdern in Italien, die beide auch als Tressler und lokale Komture aktiv gewesen sind: das der Familie des Priesters Kristoph Rieder, eines wichtigen Mannes in der Geschichte der Ballei Sizilien (Abb. 14), und das des Bruders Nikolaus Christan, eines der letzten Brüder des Ordens in Sizilien. ${ }^{45}$

Geschichte des späten Mittelalters 5), hrsg. v. W. Paravicini, Bd. I: Deutsche Reiseberichte, bearb. v. C. Halm, Frankfurt/Main ${ }^{2} 2001$, Nr. 67, S. 161-163).

411452 September 17., Die Urkunden des Deutschordens-Zentralarchivs (wie Anm. 37), Bd. III, Nr. 3696, S. 1103. Johann war in Preussen, Franken und Apulien tätig. Ein Ulrich von Trockau war schon 1301-1304 Komtur in Mergentheim (Klebes (wie Anm. 5), S. 698, und 1304 Juni 11., Ludwigsburg, Staatsarchiv, B 250, U 396).

42 Siehe M. Lurz, Die Freiherren von Venningen, Sinsheim 1997.

43 E. Lehr, L'Alsace noble, Paris 1870, S. ix.

44 Friedrich von Bobenhausen, Sohn des Konrad von B., im Januar 1391 in Frankfurt am Main in den Deutschen Orden eingetreten (W. Jost, Der Deutsche Orden in Rhein-Main Gau: ein Quellenbuch für Namenforschung, Gießen 1941, Nr. 138, S. 36; Die Urkunden des Deutschordens-Zentralarchivs (wie Anm. 37), Bd. II, Nr. 2547, S. 776); war Landkomtur in Lamparten 1400-1402. Dietrich aus der fränkischen Adelsfamilie Bobenhausen (auch Babenhausen), aus dem gleichnamigem Ort in Hessen, war im Orden seit 1494 (J. Seiler, Der Deutsche Orden in Frankfurt. Gestalt und Funktion einer geistlich-ritterlichen Institution in ihrem reichsöffentlichen Umfeld (Quellen und Studien zur Geschichte des Deutschen Ordens 61), Marburg 2003, S. 311) und Hauskomtur in Mergentheim 1519 (Klebes (wie Anm. 5), S. 712). Heinrich war Hochmeister des Ordens 1572-1585/1590.

${ }^{45}$ Nikolaus Kirsten, aus die fränkische Familie Christan oder Christans, war Priesterbruder in Sizilien von 1478 bis 1491 (siehe K. Toomaspoeg, Ultimi Teutonici di Sicilia (1491-1492), Sacra Militia. Rivista di storia degli ordini militari 2 (2001), S. 155-177). Ein Heinrich und Adelheid Christan kommen in Nürnberg in 1393 vor (1393, Dezember 15., Nürnberg, Stadtarchiv, A 1), Konrad Christan war Prior in Pappenheim (Landkreis Weissenburg-Gunzenhausen) in 1426 (1426 Dezember 6., ebd., D 2/IV, Spitalamt/Akten, Nr. 805), ein Kunz von Cristans ist in 1452 in Hessen oder Franken im Deutschen Orden eingetreten, mit Empfehlungen von Hans von Cristans und Hans Gross (1452 April 22., Die Urkunden des Deutschordens-Zentralarchivs (wie Anm. 37), Bd. III, Nr. 3687. S. 1100), ein anderer gleichnamiger war Stadtbürger in Nürnberg am Anfang des 16. Jh. (1500 August 29., Nürnberg, Stadtarchiv, A 1) Heinrich Cristan war Landschreiber und Bürger in Würzburg in 1469 (1469 Juli 11., Ludwigsburg, Staatsarchiv, B 503 I, U 996) und später findet man in der Ballei Franken einen Priesterbruder Kaspar Christan oder Christian, Komtur in Münnerstadt in 1523 und in Rothenburg ob der Tauber in 1524-1525, den den protestantischen Glauben annahm, vom Bischof von Würzburg verbannt 
Die Beziehungen waren besonders stark zu einigen Ordenshäusern wie Mergentheim, (Frankfurt-)Sachsenhausen, Würzburg, Ulm, Nürnberg und Marburg an der Lahn. Nehmen wir die Liste der Ordensbrüder in Italien, die eine persönliche Verbindung zur Kommende Mergentheim besaßen (Abb. 15). Mindestens zwei sind in Mergentheim in den Orden eingetreten, und drei gehörten zu den wichtigsten Vertrauten des Deutschmeisters: Georg Graf von Henneberg, der 1451 Ritterbruder des Deutschen Ordens geworden ist, bevor er 1454 vom Deutschmeister mit einer Gruppe von Ordensrittern und Söldnern nach Preußen gesandt wurde; 1464 nahm er an den Verhandlungen des Zweiten Thorner Friedens teil, 1479 war er Komtur in Heilbronn und Brotfelden (Stadtprozelten) in der Ballei Franken, 1482 war er Komtur in Mergentheim und 1483 Generalprokurator des Deutschen Ordens bei der römischen Kurie: als Ritterbruder aus dem Deutschmeistertum war er eigentlich ein Sonderfall in der Reihe der Generalprokuratoren in Rom. ${ }^{46}$ Danach, 1485-1506, war er wieder als Komtur in Mergentheim tätig und ist 1508 gestorben. ${ }^{47}$

Oder der Fall Dietrichs von Hasslach. Er ist 1508 in Horneck als Ritterbruder in den Orden eingetreten, war 1513-1516 Baumeister und Trapier in Mergentheim, wurde im März 1524 Balleistatthalter in Lamparten und hat von Mai bis August 1525 das Amt des Prokurators des Deutschmeisters in Rom ausgeübt. Danach war er Landkomtur in Lamparten bis zu seinem Tod während einer Reise nach Rom im November 1529. ${ }^{48}$ Mit ihm begann der Deutsche Orden die sogenannten Rekuperationsversuche seiner verlorenen italienischen Besitzungen. Ziemlich ähnlich verlief die Karriere des Ritters Philipp von Hohenstein. ${ }^{49}$

wurde, sich mit aufständischen Bauern verbündete und nach dem Ende des Bauernkriegs im Juni 1525 aus der Stadt Rothenburg flüchten musste (Nürnberg, Germanisches Nationalmuseum, Sammlung Hartmann).

46 Freytag (wie Anm. 29), S. 213; Beuttel (wie Anm. 5), S. 68 f.

47 Siehe Die Urkunden des Deutschordens-Zentralarchivs (wie Anm. 37), Bd. III, S. 1240, 1244, 1247, 1250, und Klebes (wie Anm. 5), S. 704.

48 Siehe Klebes (wie Anm. 5), S. 563, 718, 720, und die folgenden Quellen: 1524 März 12., Wien, Zentralarchiv des Deutschen Ordens, Abteilung Welschland 132, Fol. 514r-515v; 1524 April 22., Padua, Archivio di Stato, Corporazioni religiose soppresse, Gesuiti, Bd. 17, Fol. 259r259v; 1525 September 29., Wien, Zentralarchiv des Deutschen Ordens, Abteilung Welschland 128/1, Fol. 266r-267r; 1529 Mai 21., Protokolle der Kapitel und Gespräche des Deutschen Ordens im Reich (1499-1525) (Quellen und Studien zur Geschichte des Deutschen Ordens 41, Veröffentlichungen der Internationalen Historischen Kommission zur Erforschung des Deutschen Ordens 3), hrsg. v. M. Biskup, I. Janosz-Biskupowa, Marburg 1991, S. 119; 1529 August 23., Wien, Zentralarchiv des Deutschen Ordens, Urkunden, 1530 Juli 5.; ebd., Abteilung Welschland 124/2, Fol. 278r-278v.

49 Siehe Forstreuter (wie Anm. 2), S. 156; Protokolle der Kapitel (wie Anm. 48), S. 135, 157, 160; Klebes (wie Anm. 5), S. 626. 
Von 1365 bis zum Ende des mittelalterlichen Deutschen Ordens haben die Deutschmeister die italienischen Balleien relativ sorgfältig verwaltet. In zwei Fällen sind auch Quellen über persönliche Beziehungen der Deutschmeister zu Italien vorhanden. So hat Eberhardt von Seinsheim im Sommer 1433 die Balleien Apulien und Sizilien besucht (als Erinnerung an seine Reise wurde sein freskiertes Wappen auf die Chorwand der Ordenskirche St. Leonhard in Siponto gemalt) und ist danach weiter in die Ballei Lamparten gereist. ${ }^{50}$ Andreas von Grumbach, Deutschmeister 1489-1499, hatte bereits 1462, als er noch Komtur in Regensburg war, die Ballei Lamparten als deutschmeisterlicher Visitator besucht. ${ }^{51}$

Die deutschmeisterliche Verwaltung, die auf persönlichen Interventionen der Deutschmeister wie Philipp von Bickenbach und Eberhardt von Seinsheim und auf regelmäßigen und detailliert durchgeführten Visitationen basierte ${ }^{52}$, war jedoch nicht problemlos. Gleichzeitig stellte sich im 15. Jahrhundert zum ersten Mal auch die Frage der Inkompetenz und des Ungehorsams von Ordenbrüdern.

Im Allgemeinen kann man behaupten, dass die übliche moralische Schwächung der Brüder des Deutschen Ordens im Laufe des 15. Jahrhunderts in Italien wegen ihrer Isolation besonders sichtbar und gefährlich wurde..$^{53}$ Als Folge der Rivalität zwischen Deutschmeistern und Hochmeistern wurde die Leitung der Balleien auf der Halbinsel sehr unsicher, und einige lokale Ordensmitglieder konnten davon profitieren, um eigenen Interessen nachzugehen. ${ }^{54}$ Eines der Hauptprobleme war zweifellos, dass es für die Halbinsel nicht genügend Brüder gab, was wohl mit ähnlichen Schwierigkeiten in den Balleien im deutschsprachigen Raum zusammenhing. Jedoch fangen diese Versorgungsprobleme relativ spät an, erst um 1460, als der Deutschmeister Ulrich von Lentersheim nicht in der Lage war, seine Macht voll auszuüben und als die schweren Umstände des Ordens in Preußen keinen Raum für ein Interesse an Italien gelassen haben. Das Problem war also gleichzeitig ein moralisches und ein politisches, jedoch nicht nur auf die Halbinsel begrenzt.

50 E. Kittel, Deutschordens-Wappen an der Adria und der Deutschmeister Eberhard von Seinsheim, in: Der Herold. Vierteljahrsschrift für Heraldik, Genealogie und verwandte Wissenschaften 7 (1972), S. 321-334; La contabilità delle Case dell'Ordine Teutonico in Puglia e in Sicilia nel Quattrocento (Acta Theutonica 2), hrsg. v. K. Toomaspoeg, Galatina 2005, S. xix; C. A. Lückerath, Saunsheim, Eberhard von, in: Neue Deutsche Biographie, Bd. 22, Berlin 2005, S. 464-465.

51 1462, Visitationen, Bd. III (wie Anm. 10), Nr. 182c, S. 240.

52 Siehe La contabilità delle Case (wie Anm. 50).

53 Siehe Toomaspoeg, Ultimi Teutonici (wie Anm. 45).

54 Siehe B. Schumacher, Studien zur Geschichte der Deutschordensballeien Apulien und Sizilien, Altpreußische Forschungen 18 (1941), S. 187-230; 19 (1942), S. 1-25. 


\section{SCHLUSSFOLGERUNGEN}

Zum Schluss dieses Überblicks möchte ich anmerken, dass sich das Erscheinungsbild der Brüder des Deutschen Ordens in Italien im Laufe der Zeit stark veränderte. Von einer Situation, in der die Balleien im Wesentlichen von Rheinländern kontrolliert wurden, ging die Entwicklung zu einer anderen, in der die Kontrolle fest in der Hand der Brüder aus Franken, Schwaben und Hessen lag.

Zur Zeit der Verwaltung der Deutschmeister in Italien kann man beobachten, wie eine relativ begrenzte Gruppe von ritterlichen Familien, wie die der Berlichingen, Bobenhausen, Heusenstamm, Scheckenbach, Trockau, Uissigheim, Urbach, Venningen und anderen den Hauptteil der Ordensbrüder stellte.

Es handelte sich normalerweise nicht um Familien mit besonders starkem sozialem oder wirtschaftlichem Hintergrund, und meistens waren es Lehensträger der großen Territorialherren, wie etwa die Familie Seeburg in Urach, die, wie etliche andere, aus dem Einflussbereich der Grafen (dann Herzöge) von Württemberg kam. Eine andere wichtige Gruppe von Ordensmitgliedern, deren genaue Zahl sicherlich sehr viel bedeutender war als die überlieferten Quellen zeigen, kam aus dem Stadtpatriziat.

So haben wir es also mit zwei sozialen Netzwerken zu tun: einerseits den kleineren Familien von Rittern und Edelknechten mit einer engen Beziehung zu Ordenshäusern wie Mergentheim, (Frankfurt-)Sachsenhausen oder Marburg an der Lahn, und zweitens den adeligen und bürgerlichen Stadtfamilien aus Frankfurt am Main, Nürnberg, Mergentheim und anderswo. Die Brüder städtischer Herkunft waren meistens - wenngleich nicht immer - als Priesterbrüder, die Landesadeligen als Ritterbrüder tätig.

Der Ordenseintritt und ein Aufenthalt in Italien konnten sicherlich als eine Karrieremöglichkeit für jüngere Söhne der Adelsfamilien betrachtet werden. Jedoch muss man auch daran erinnern, dass einige Verwandte der Ordensbrüder in Italien im 15. Jahrhundert als Pilgerreisende im Heiligen Lande vorkommen; es geht dabei vor allem um die Nürnberger Familien Lochner, Pfinzing und Rieder/ /Rieter. ${ }^{55}$ Dass die Vertreter derselben Familien gleichzeitig als Ordensbrüder in Franken und Italien und als Pilgerreisende vorkommen, ist ein Zeugnis für Familientradition und Spiritualität der Epoche.

Die italienischen Quellen, die ich hier kurz darzustellen versucht habe, bieten somit etliche Auskünfte zur Personalgeschichte des Deutschmeistertums und der Übergangsepoche zwischen dem mittelalterlichen und neuzeitlichen Deutschen Orden.

55 Europäische Reiseberichte (wie Anm. 40), Nr. 25, S. 79-81; Nr. 28, S. 85-87. 


\section{ANHANG}

Abb. 1: Kategorien von Ordensbrüdern in Italien

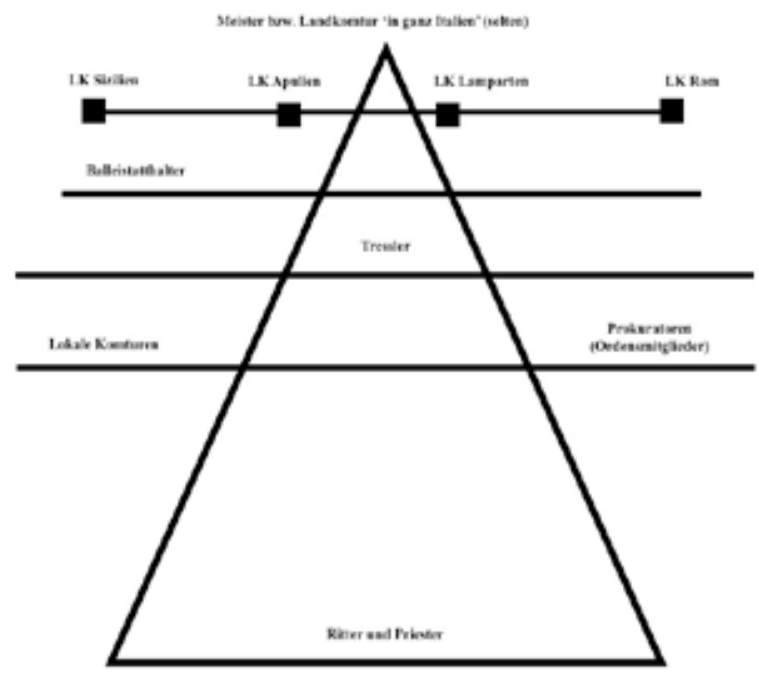

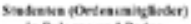
th Beleras and Pinjer

Abb. 2: Lebenslauf eines Ordensbruders in Italien: Beispiel des Götz von Berlichingen

Götz von Berlichingen (Gofredus de Perlechim, Gofredus quondam nobilis viri domini Tederici, Gotferdus de Perlechim, Gozus, Gucius de Plechim, Guoze, Guc quondam domini Thederici de Alemania, nobilis frater Gotifredus natus quondam domini Tedrici de Perlengingem de Alemania Alta).

Götz, Sohn des Dietrich von Berlichingen, ist im Februar 1374 in den Deutschen Orden in Mergentheim (B. Franken) eingetreten (Ludwigsburg, Staatsarchiv, B 236, Bueschel 121). 1408-1409 findet man ihn als Balleistatthalter in Lamparten und danach, bis ca. 1418, als Landkomtur der Ballei. Er stammt aus dem gut bekannten Geschlecht (E. H. Kneschke, Neues allgemeines Deutsches Adels-Lexicon, Leipzig 1859 (Neudr. Hildesheim-New York 1973), Bd. I, S. 355-358) und 
ist ein Vorfahre des gleichnamigen Ritters 'mit der eisernen Hand'. Die Berlichingen waren dem Deutschem Orden zugewandt, mit besonders engem Verhältnis zur Kommende Mergentheim (siehe Klebes (wie Anm. 5), wo die Angehörigen der Familie oft vorkommen). Am gleichen Tag wie Götz ist auch sein Bruder Dietrich in den Orden eingetreten; in seinem Fall sind auch die Bürgen bekannt: Hans von Berlichingen (Sohn des Ulrich Taube von Berlichingen), Beringer Kruppel und Kunz Reymar (Die Urkunden des Deutschordens-Zentralarchivs (wie Anm. 37), Bd. II, Nr. 2313, S. 711).

Quellen: 1408 Juni 19., Padua, Archivio di Stato, Corporazioni religiose soppresse, Gesuiti, Bd. 166, Nr. 3; 1409 Juli 22., ebd., Bd. 163, Nr. 15; 1409 September 7., ebd., Bd.163, Nr. 5; 1410 März 8., ebd., Bd. 163, Nr. 9; 1410 Dezember 10., ebd., Bd. 166, Nr. 23; 1410 Dezember 15., ebd., Bd. 166, Nr. 16; 1411 April 8., ebd., Bd. 163, Nr. 22; 1411 August 27., ebd., Bd. 163, Nr. 12; 1412 Januar 18., ebd., Bd. 166, Nr. 10; 1413 April 5., ebd., Bd. 166, Nr. 20; 1418 September 29., ebd., Bd. 163, Nr. 14.

Literatur: Forstreuter (wie Anm. 2), S. 156.

Abb. 3: Herkunftsgebiete der Ordensbrüder in Italien

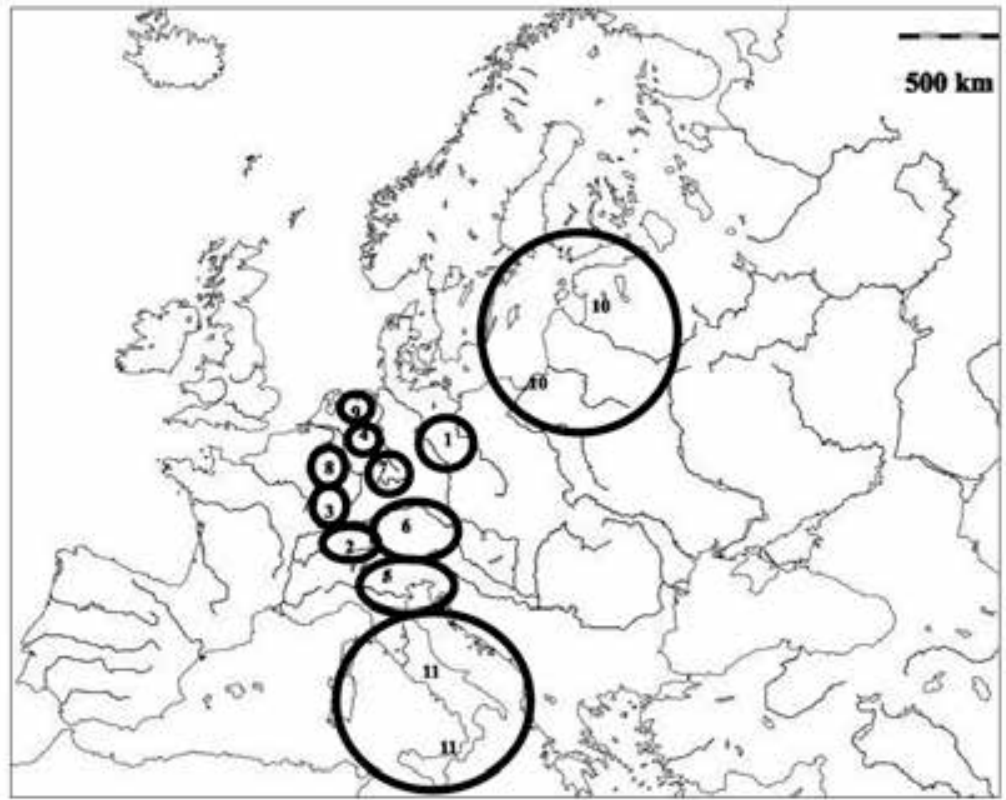


1. 'Sachsen-Thüringen' (Balleien Sachsen und Thüringen mit Grenzen nach 1255); 2. 'Schweiz'; 3. 'Elsass, Lothringen, Saarland und Luxemburg' (besteht im Hauptteil aus der Ballei Lothringen); 4. 'Mittelrhein' (südlicher Teil der Ballei Westfalen); 5. 'Tirol und Österreich'; 6. 'Schwaben, Franken und Altbayern' (im Großen und Ganzen die gesamte Ordensballei Franken und der südöstlicher Teil der Ballei Elsass-Burgund, ohne Elsass und Schweiz); 7. 'Hessen' (Ballei Hessen); 8. 'Nordrhein, Westfalen und Niedersachsen' (Ballei Koblenz, der nördliche Teil der Ballei Westfalen und ein Teil der Ballei Biesen); 9. 'Niederlande'; 10. 'Preußen und Livland'; 11. 'Italien'.

Abb. 4.1-3: Herkunftsgebiete der Ordensbrüder in Italien: Zeitentwicklung 1.

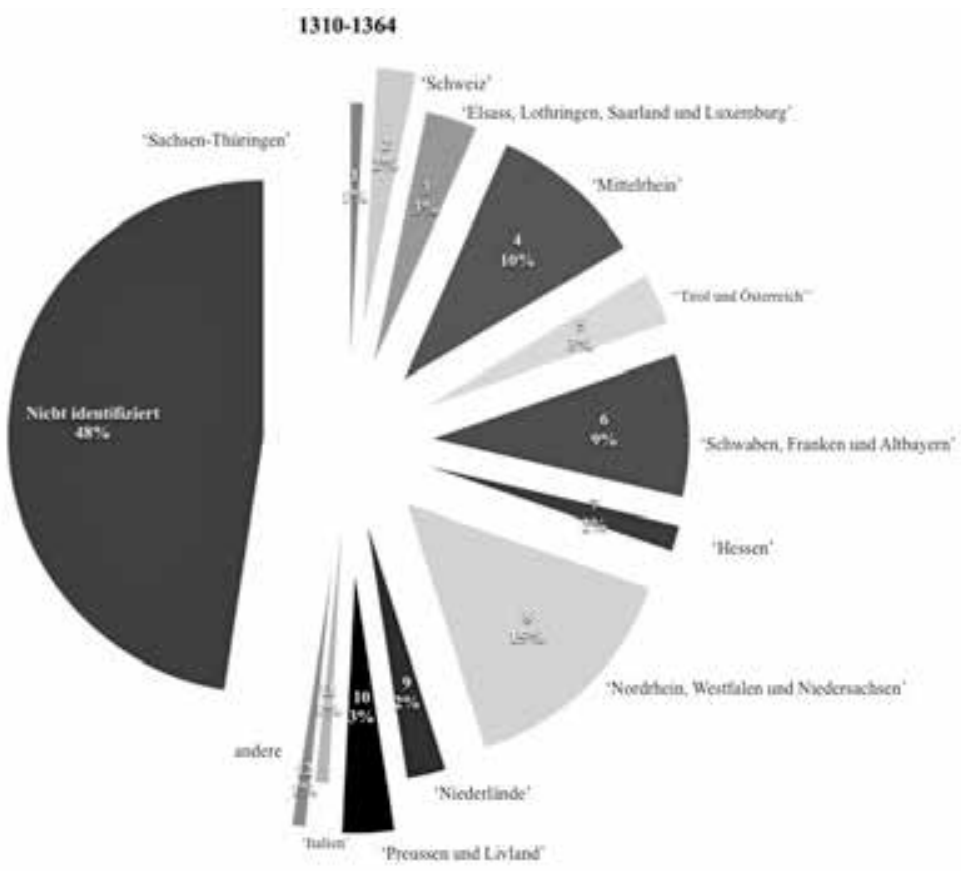


2.

1365-1450

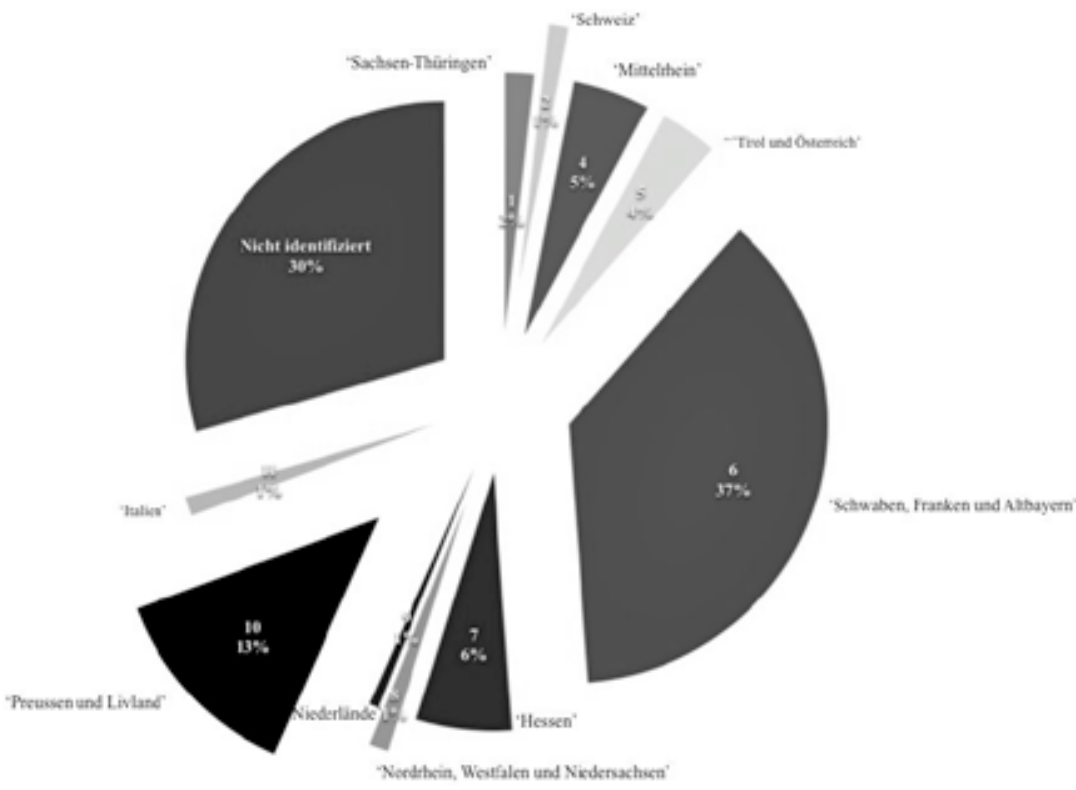

1451-1534

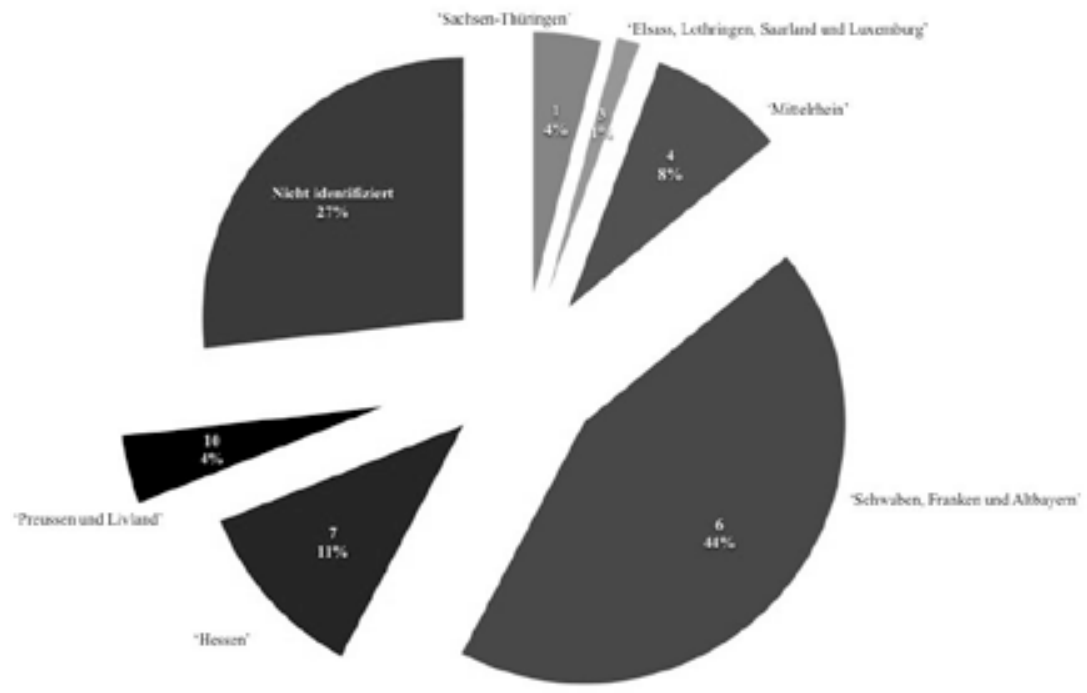


Abb. 5: Anzahl der Ordensbrüder aus Franken und Schwaben

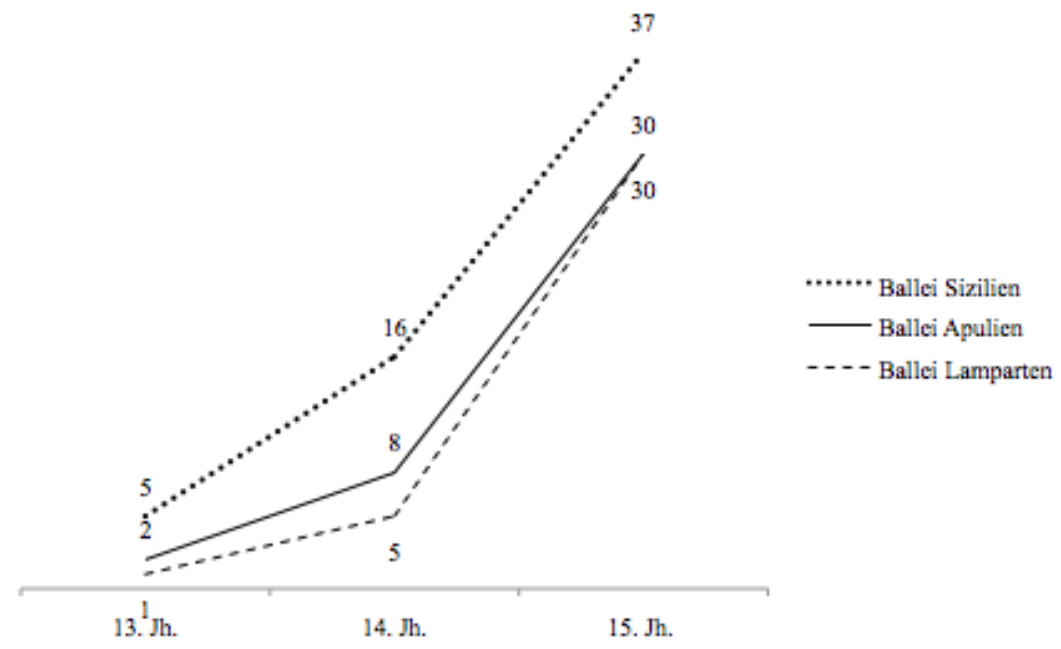

Abb. 6: Städtische Herkunft der Ordensbrüder

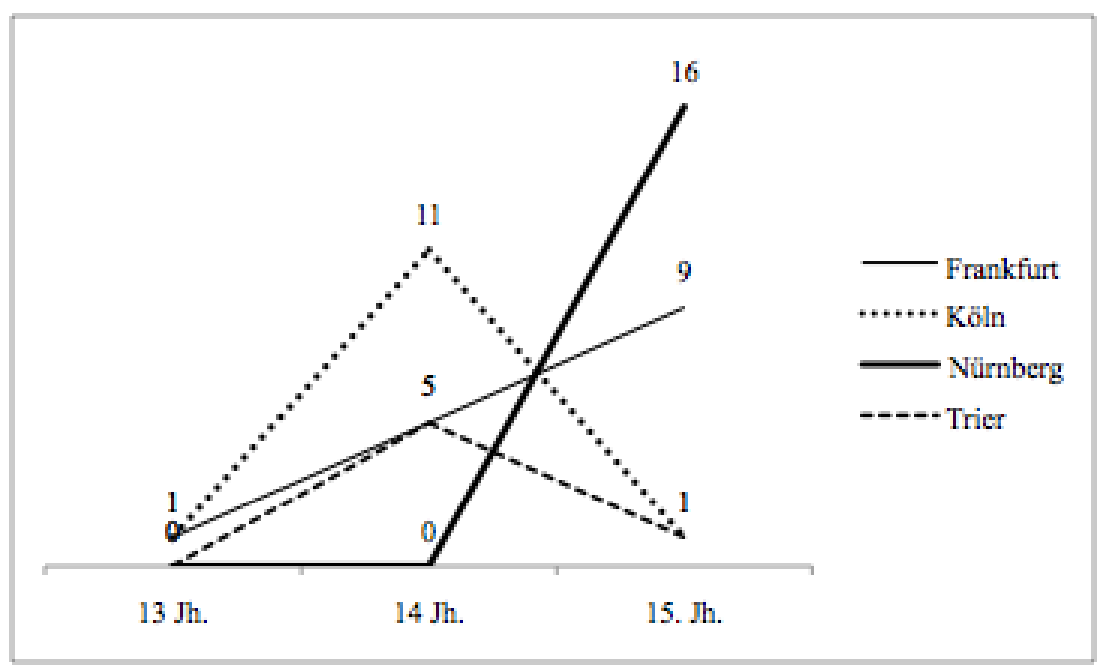


Abb. 7.1: Amtsdauer der gesamten Ordensbrüder in Italien

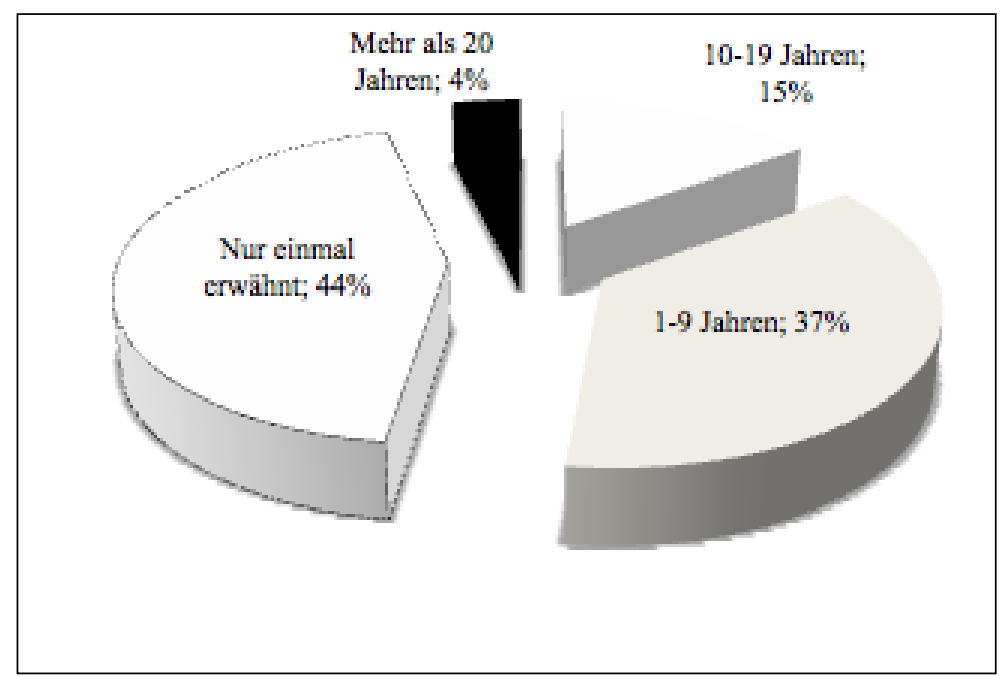

Abb. 7.2: Amtsdauer der Landkomture

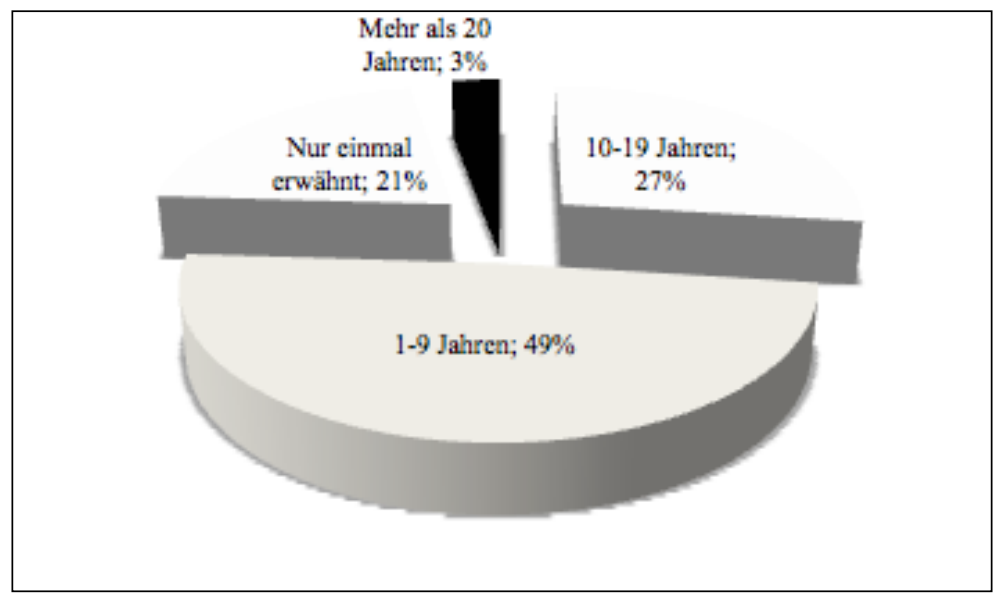


Abb. 8: Vorige und folgende Dienststellen der Ordensbrüder in Italien

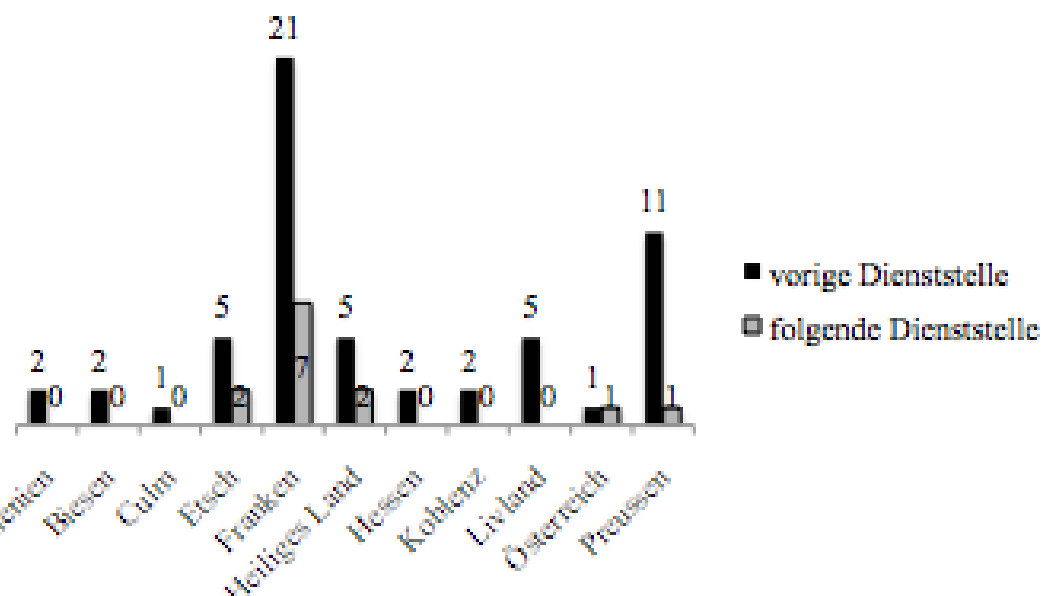

Abb. 9: Die Familie Ulrichs von Schmalenstein

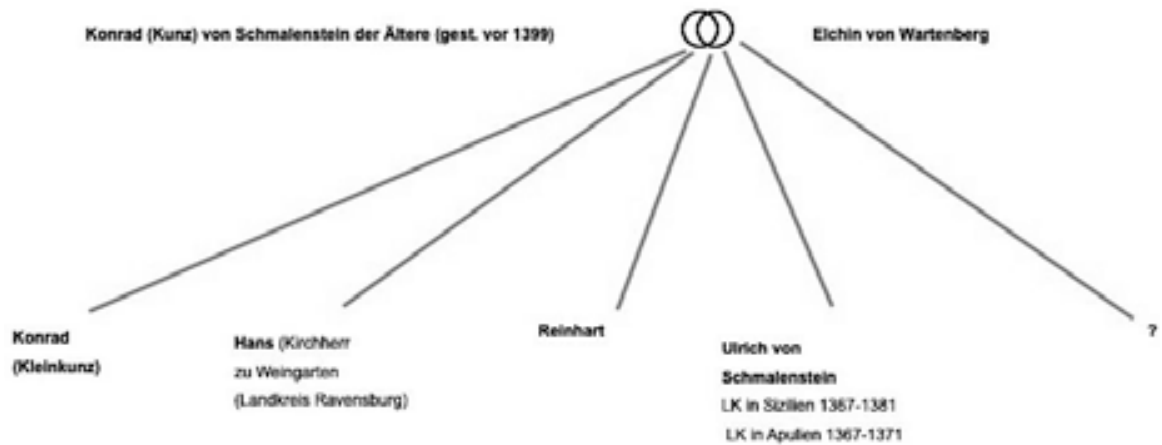

Abb. 10: Die in Italien tätigen Ordensbrüder aus Nürnberg

Wilhelm Behaim: Landkomtur in Lamparten 1438-1439 und in Sizilien 1442$-1453$

Wilhelm Behaim: Bruder in Padua (Lamparten) 1487

Ulrich Filzhut: deutschmeisterlicher Visitator in Sizilien 1430, dann Komtur in Rothenburg und Priesterbruder in Heilbronn 
Hans Haidenaab: Sohn des Nürnberger Söldners Konrad von H., 1400 in Franken in den Orden eingetreten. Ritterbruder in Ellingen 1426, bald danach nach Apulien gesandt, später auch in der Ballei Lamparten tätig

Peter Haidenaab: Bruders des vorigen, Landkomtur in Lamparten 1442-1447

Markus Koler: Bruder in Palermo (Sizilien) 1418

Ulrich Koler: Ritterbruder in Franken, Lamparten und Apulien 1443-1451

Hans Lochner: Komtur in Venedig und Padua (Lamparten) 1470-1471, Bruder in Palermo (Sizilien) 1478-1491

Paul Pfinzing: Ritterbruder in Lamparten seit 1451

Wilhelm von Rabenstein: Bruder in Apulien 1442-1448

Konrad Teufel: Priesterbruder in Palermo seit 1416, Tressler in Sizilien 1428-1440, Balleistatthalter in Sizilien 1437; Komtur in Messina 1440-1442

Abb. 11: Netzwerke: Rittergeschlecht Heusenstamm (Hessen)

Henne Burghard gen. von Husenstam: hat 1391 in Frankfurt am Main beim Ordenseintritt Friedrichs von Bobenhausen gebürgt

Ekart von Husenstam: 1447 Zeuge einer Urkunde der Kommende Frankfurt (-Sachsenhausen)

Werner von Heusenstamm: Komtur in Palermo (Ballei Sizilien) 1403

Werner alias Gewar, Gybor oder Yvor von Heusenstamm: 1446 in Frankfurt am Main in den Orden eingetreten, Ritterbruder in Brandenburg/Preußen 1447 und 1451

Philipp von Heusenstamm (gest. 1543): 1491 in Frankfurt in den Orden eingetreten, Komtur in Frankfurt 1504-1508, Rat des Deutschmeisters 1515, Administrator des Ordensbesitzes in Preußen 1527, Komtur in Regensburg 1530

Walter von Heusenstamm: Komtur in Kapfenburg und Weissenburg und Landkomtur in Koblenz 1522-1531

Abb. 12: Netzwerke: Geschlecht Urbach (aus Schorndorf (Rems-Murr-Kreis, Württemberg)

Anselm von Urbach: Komtur in Heilbronn und in Horneck 1314-1330

Friedrich von Urbach: Komtur in Mergentheim 1336, Landkomtur in Franken $1339-1340$ 
Albert von Urbach, Komtur in Padua (Ballei Lamparten) 1366, Bruder in Palermo (Ballei Sizilien) 1367 und 1377

Wolf von Urbach, Bruder und Komtur in Prozelten 1381-1401

Jakob, Konrad und Wolf von Urbach: Brüder in Preußen 1391-1462

Abb. 13: Netzwerke: Geschlecht Venningen

Dietrich von Venningen: Landkomtur in Elsass-Burgund 1370-1374, Komtur in Mergentheim 1379, Landkomtur in Franken 1392-1394, Komtur in WeiBenburg 1396-1408

Siegfried von Venningen: Deutschmeister 1382-1393

Siegfried von Venningen: Landkomtur in Sizilien 1389-1390, Komtur in Weinheim 1422 (?)

Johann von Venningen: Bruder in Franken 1396-1426, Landkomtur in Lothringen 1430

Jost von Venningen: Deutschmeister 1447-1454

Abb. 14: Netzwerke: Geschlecht Rieder

Weiprecht von Riedern: Johanniter in Mergentheim 1390

Kristoph Rieder: Bruder und Tressler in Sizilien 1440 - um 1460

Peter von Riedern: Priesterbruder in Mergentheim 1451, Komtur in Ellingen, Nürnberg und Rothenburg o.d. Tauber 1463-1495

Sebald Rieter der Ältere: Autor der Berichte seiner Pilgerreisen nach Rom, Santiago de Compostela und ins Heilige Land 1450-1479

Abb. 15: Ordensbrüder in Italien mit Beziehungen zum Ordenshaus Mergentheim

Götz von Berlichingen (Balleistatthalter und Landkomtur in Lamparten 1408-1418): im Februar 1374 in Mergentheim in den Orden eingetreten

Hans von Scheckenbach von Ehinheim (Bruder in Sizilien 1404-1405): im Oktober 1400 in Mergentheim in den Orden eingetreten

Wilhelm Lochner (Bruder in Sizilien und Lamparten 1463-1464): aus einer bürgerlichen Familie in Mergentheim, Küchenmeister in Mergentheim 1451

Georg von Henneberg (Generalprokurator in Rom 1484): Komtur in Mergentheim 1483 und 1485-1499 
Kaspar von Carben (Komtur in Bologna 1508-1511): Ritterbruder in Mergentheim 1501

Philipp von Hohenstein (Landkomtur in Lamparten 1498-1504): Mitglied der St. Georgs-Bruderschaft in Mergentheim 1506

Dietrich von Hasslach (Landkomtur in Lamparten und Prokurator des Deutschmeisters in Rom 1524-1526): 1508 in Horneck als Ritterbruder in den Deutschen Orden eingetreten; Baumeister und Trapier in Mergentheim 1513-1514

Heinrich Schilling (Komtur in Brixenei 1532-1534): Bruder in Mergentheim 1526

\section{SUMMARY \\ The Brethren of the Teutonic Order in Italy}

The history of the Teutonic Knights in Italy is an area of research that during the last two decades has brought new insights and offered new approaches to the study of the Teutonic order as well as other military orders. One of the most interesting aspects of this subject is represented by the existing prosopographical sources about the Teutonic brethren in Italy.

The article presents initial results of a wider research on this topic, examining the names of 580 Teutonic knights and priests in Italy from 1202 to 1534. The first part provides some short and general statistical information about questions like the number of brethren, their categories, careers and origins. The second part presents more detailed studies concerning the period from 1365 to 1534, when Italian provinces of the Teutonic Order (Lombardia, Apulia and Sicilia) were no longer ruled by the Grand Master himself but by the Master of Germany (Deutschmeister). The analysis focuses on the geographical and social origins of Italian brethren and their evolution from the $13^{\text {th }}$ century onwards as well as on the career models and options of the Order's brethren and the relations between Teutonic houses in southern and central Germany and the Italian commanderies. The results confirm the existence of a network of contacts between the members of the Order in German and Italy. The network was based on a range of social groups, particularly smaller knightly families of Franconia and Hessen as well as citizens of Frankfurt am Main and Nuremberg. 
